\title{
Analysis and characterization of heparin impurities
}

\author{
Szaboles Beni • John F. K. Limtiaco • Cynthia K. Larive
}

Received: 25 June 2010 /Revised: 9 August 2010 / Accepted: 10 August 2010 / Published online: 3 September 2010

(C) The Author(s) 2010. This article is published with open access at Springerlink.com

\begin{abstract}
This review discusses recent developments in analytical methods available for the sensitive separation, detection and structural characterization of heparin contaminants. The adulteration of raw heparin with oversulfated chondroitin sulfate (OSCS) in 2007-2008 spawned a global crisis resulting in extensive revisions to the pharmacopeia monographs on heparin and prompting the FDA to recommend the development of additional physicochemical methods for the analysis of heparin purity. The analytical chemistry community quickly responded to this challenge, developing a wide variety of innovative approaches, several of which are reported in this special issue. This review provides an overview of methods of heparin isolation and digestion, discusses known heparin contaminants, including OSCS, and summarizes recent publications on heparin impurity analysis using sensors, near-IR, Raman, and NMR spectroscopy, as well as electrophoretic and chromatographic separations.
\end{abstract}

Keywords Contamination · Impurity · Heparin · NMR . OSCS · Adulteration

Published in the special issue Heparin Characterization with Guest Editor Cynthia K. Larive.

S. Beni · J. F. K. Limtiaco • C. K. Larive $(\bowtie)$

Department of Chemistry, University of California,

Riverside, CA 92521, USA

e-mail: clarive@ucr.edu

S. Beni

Department of Pharmaceutical Chemistry,

Semmelweis University,

Högyes Endre u. 9 ,

1092 Budapest, Hungary

\section{Introduction}

The scope of this critical review is to summarize and discuss the recent analytical developments in the exploding field of heparin impurity analysis a little over two years after the intentional contamination of pharmaceutical heparin with oversulfated chondroitin sulfate (OSCS) [1] In fall 2007 and early 2008 serious adverse events associated with heparin administration were reported. Acute, allergic-type reactions were observed among patients undergoing hemodialysis and after intravenous infusion of unfractionated heparin [2, 3]. This adulteration made the news and put heparin, one of the oldest drugs, into the limelight. The consequences of the concomitant health crisis are known; contaminated heparin was associated with over 200 deaths around the world. Regulations were subsequently revised to ensure drug safety, and sweeping changes in the analytical methods required for heparin quality assurance were simultaneously implemented [4]. Following previous reviews on heparin analysis [5] and the lessons learned from the recent crisis [6], this paper reviews the latest analytical methods for heparin impurity analysis and provides some future prospects.

Heparin is a member of the glycosaminoglycan (GAG) family. It is a polydisperse mixture of sulfonated linear polysaccharides consisting of 1-4 linked and variously modified uronic acid and D-glucosamine repeating disaccharide subunits (Fig. 1) [7]. Compared to other GAG biopolymers, such as chondroitin sulfate, dermatan sulfate, keratan sulfate and hyaluronic acid, heparin is structurally the most complex polysaccharide. The uronic acid of heparin may be either $\alpha$-L-iduronic (IdoA) or $\beta$-Dglucuronic acid (GlcA) and can be unsubstituted or sulfonated at the 2-O position. The glucosamine residue may be unmodified $(\mathrm{GlcN}), N$-sulfonated (GlcNS) or $N$ - 


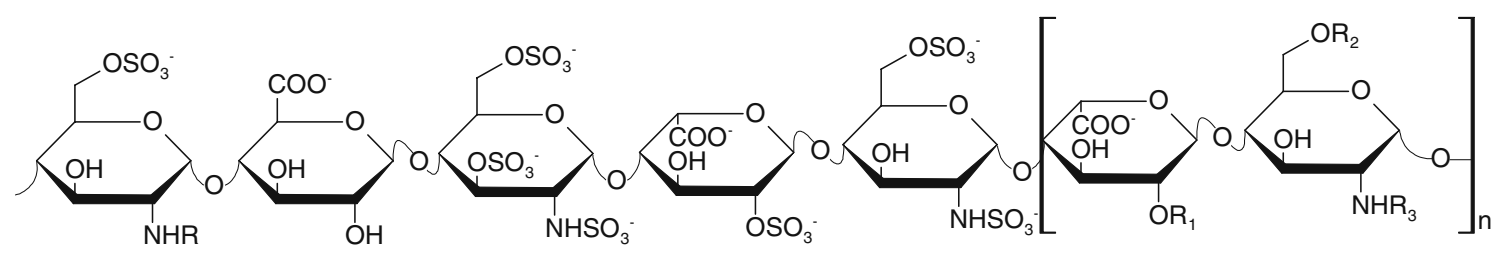

Fig. 1 The unique antithrombin III binding pentasaccharide sequence and repeating disaccharide units of heparin. $\left(\mathrm{R}_{1}=\mathrm{H}, \mathrm{SO}_{3}{ }^{-} ; \mathrm{R}_{2}=\mathrm{H}, \mathrm{SO}_{3}{ }^{-}\right.$; $\mathrm{R}_{3}=\mathrm{H}$, acetyl, $\mathrm{SO}_{3}{ }^{-}$)

acetylated (GlcNA), and can contain variable patterns of $O$-sulfonation at the $3-O$ and $6-O$ positions. The major disaccharide sequence of heparin is the trisulfonated LIdoA(2S)-D-GlcNS(6S), which comprises roughly $70 \%$ of heparin from porcine intestinal mucosa $[7,8]$. The related GAG heparan sulfate is a proteoglycan component of many cell-surface receptors and an integral part of the extracellular matrix [9]. Although based on the same basic disaccharide subunit, the sulfonate content of heparan sulfate is lower than heparin, with a GlcNA to GlcNS ratio of $>3$, and heparan sulfate has about twice the level of glucuronic as iduronic acid. Consequently, a GAG qualifies as heparin only if the content of $N$-sulfo groups greatly exceeds that of $N$-acetyl groups and the concentration of $O$-sulfo groups exceeds that of $N$-sulfonate [10].

Heparin is biosynthesized as a proteoglycan in a multistep process involving various enzymes in the endoplasmatic reticulum and the Golgi apparatus of the mast cells of connective tissues [7,9]. The microheterogeneous structure of heparin arises during biosynthesis through reactions catalyzed by $N$-deacetylase, $N$ - and $O$-sulfotransferase and epimerase enzymes. Heparin is stored together with histamine and mast cell basic proteases in secretory granules and released into the extracellular space upon immunoglobulinE-receptor stimulation [11, 12]. Heparin is involved in the mediation of many biological functions, such as cell differentiation, proliferation and migration, adhesion and host-pathogen interactions, mainly through interactions with basic amino acid rich motifs of proteins [13-16].

Despite its involvement in these various biological processes, heparin is best known as an intravenous anticoagulant. Heparin was introduced into medical practice in the 1930s, so it is one of the oldest drugs currently in widespread clinical use [17]. Heparin's anticoagulant activity is due to the binding of a unique pentasaccharide sequence (as shown in Fig. 1) containing a 3- $O$-sulfo moiety to the protease inhibitor antithrombin III, causing a conformational change that increases the flexibility of its reactive site loop and thus its binding affinities for thrombin and factors IXa and $\mathrm{Xa}[18,19]$.

The large-scale industrial production of pharmaceutical heparin begins with its isolation from mainly porcine intestinal mucosa or whole intestine. As the natural sources of heparin are diverse and the production of raw heparin is not under strict control, the variability in the chemical profile of raw heparin is not surprising. Consequently, some variability is retained in pharmaceutical-grade heparin, even after well-regulated purification processes [6]. The molecular weight of natural (unfractionated) heparin is in the range of 5-40 $\mathrm{kDa}$, although in the vast majority of preparations the $12-15 \mathrm{kDa}$ chains predominate. The main drawback of heparin administration resides in the poor predictability of coagulation parameters. To overcome this limitation, low molecular weight heparins (LMWHs) were introduced into clinical use [20]. A further success of the clinical application of LMWHs resides in their enhanced subcutaneous bioavailability and improved pharmacokinetics [21]. LMWHs are manufactured from unfractionated heparin by controlled depolymerization, resulting in average molecular weights of $4-6 \mathrm{kDa}$ [22]. Among the currently marketed LMWHs, tinzaparin is processed via the digestion of heparin using heparin lyase enzyme, while nadroparin and dalteparin are prepared by nitrous acid depolymerization. Enoxaparin is prepared by benzylation and alkaline hydrolysis, while ardeparin and cantaxarin are produced by oxidative fragmentation of the parent polysaccharide using hydrogen peroxide and periodate, respectively [23, 24].

\section{Heparin impurities}

Considering the animal source of pharmaceutical heparin, the numbers of potential impurities are relatively large compared with a wholly synthetic therapeutic agent. The range of possible biological contaminants includes viruses, bacterial endotoxins, transmissible spongiform encephalopathy (TSE) agents, lipids, proteins and DNA. During the preparation of pharmaceutical-grade heparin from animal tissues, impurities such as solvents, heavy metals and extraneous cations can be introduced. However, the methods employed to minimize the occurrence and to identify and/or eliminate these contaminants are well established and listed in guidelines and pharmacopoeias. The major challenge in the analysis of heparin impurities is the detection and identification of structurally related impurities.

The most prevalent impurity in heparin is dermatan sulfate (DS) [25], also known as chondroitin sulfate B. The 
building block of DS is a disaccharide comprised of 1,3linked $N$-acetyl galactosamine (GalN) and a uronic acid residue, connected via 1,4 linkages to form the polymer. DS is composed of three possible uronic acid (GlcA, IdoA or IdoA2S) and four possible hexosamine (GalNAc, GalNAc4S, GalNAc6S or GalNAc4S6S) building blocks. The presence of iduronic acid in DS distinguishes it from chrondroitin sulfate $\mathrm{A}$ and $\mathrm{C}$ and likens it to heparin and HS [26]. DS has a lower negative charge density overall compared to heparin. A common natural contaminant, DS is present at levels of $1-7 \%$ in heparin API, but has no proven biological activity that influences the anticoagulation effect of heparin.

The chondroitin sulfate class of GAGs is comprised of 1,3-linked GlcA and GalN residues. The pattern of sulfonation helps to classify the GAGs into CSA (GalNAc4S), CSC (GalNAc6S), CSD (GlcA2S and GalNAc6S), and CSE (GalNAc4S6S). The terms highly

(a)

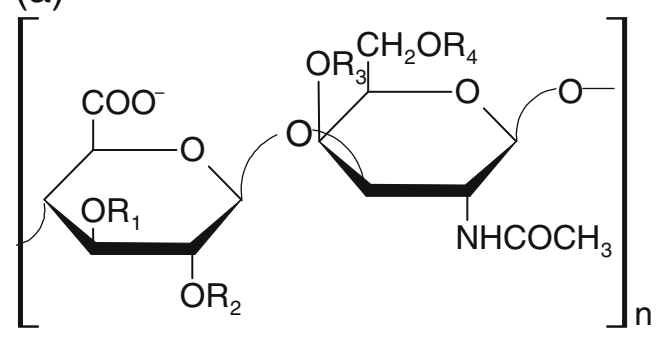

(b)

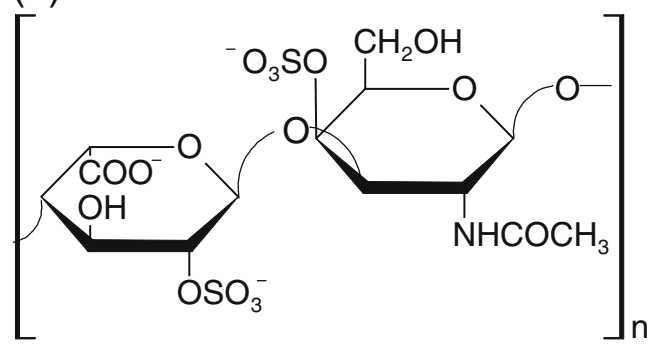

(c)

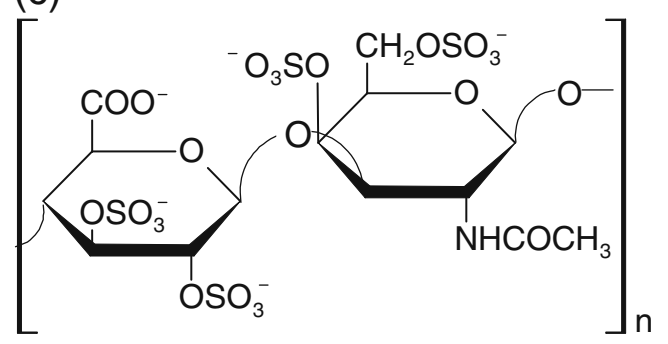

Fig. 2 Major repeating disaccharide units of heparin-like GAGs: a CS; b DS; c OSCS. The backbone of DS is not homogeneous; the vast majority of the uronic acid residues are IdoA, but DS also contains minor amounts of GlcA. The backbones of CS and OSCS are homogeneously composed of GlcA. For CS, $\mathrm{R}_{1}-\mathrm{R}_{4}$ can be either sulfonated or unsubstituted or fully sulfated chondroitin sulfate (FSCS) refer to a naturally occurring sequence bearing three sulfonates per disaccharide unit. However, "oversulfated chondroitin sulfate" (OSCS) is a semisynthetic compound containing four sulfonate groups per building block [1, 27]. The structural differences between DS, CS, and OSCS are illustrated in Fig. 2.

\section{OSCS adulteration of heparin}

A detailed description of events related to the OSCS adulteration of heparin is summarized on the US Food and Drug Administration (FDA) website [28]. The first observation of serious adverse events in patients undergoing heparin therapy was made on 19 November 2007 at the Children's Hospital in St. Louis, MO, USA, which was followed by additional cases in January 2008. The marked increase in allergic reactions following heparin administration was reported to the Centers for Disease Control and Prevention (CDC). The CDC alerted the FDA to this problem on 4 January 2008. Five days later, a connection between the suspected lots of heparin and Baxter Healthcare emerged, and Baxter initiated the urgent voluntary recall of nine lots of single- and multidose heparin vials on 17 January and all of its heparin products on 28 February, when it stopped heparin production. On 14 February the Chinese company Changzhou SPL was identified as the source of contaminated heparin which was spread worldwide, affecting more than ten countries. Besides Changzhou SPL, the contaminant was traced by the FDA to 11 other Chinese companies in the heparin API supply chain, contributing to the extended crisis [28].

The administration of contaminated heparin lots was associated with the acute, rapid onset of a potentially fatal allergic reaction $[1,2]$. These adverse reactions resulted in over 200 deaths, which were attributed to hypotension triggered by anaphylactic shock $[1,2,6]$, prompting the FDA to identify the contaminant while working in collaboration with scientists in industry and academia. By 5 March 2008, equipped with preliminary data obtained by the combined use of optical rotation, capillary electrophoresis (CE), and ${ }^{1} \mathrm{H}$ NMR, the FDA announced that the contaminant was a "heparin-like" molecule. The following day the FDA posted protocols for using NMR and CE to screen heparin batches for the contaminant. After these safeguards were put into place, the number of adverse reactions returned to background levels. In a matter of weeks, the multidisciplinary team led by Ram Sasisekharan at the Massachusetts Institute of Technology identified and presented the structure of the contaminant to the FDA. Two days later, on 19 March, the agency announced that the contaminant was OSCS, a structurally unique glycosami- 
noglycan with an unnatural sulfonation pattern. The physicochemical properties of the isolated contaminant were in good agreement with those of chemically synthesized OSCS [27]. According to our present knowledge, OSCS is not a natural product arising from animal sources. Therefore, it must be concluded that this was not a case of accidental contamination, but that OSCS was intentionally added to the raw heparin product as an act of purposeful adulteration.

The detection and the subsequent identification of OSCS as the heparin contaminant relied heavily on CE and NMR, especially ${ }^{13} \mathrm{C}$ and multidimensional NMR methods (Fig. 3). The first information about the contaminant's structure was provided by simple ${ }^{1} \mathrm{H}$ and ${ }^{13} \mathrm{C}$ NMR experiments. In addition to the $N$-acetyl resonances belonging to both heparin $(2.04 \mathrm{ppm})$ and DS (2.08 ppm), a known heparin impurity [25], an unusual $N$-acetyl signal at $2.16 \mathrm{ppm}$ was observed in heparin lots associated with the adverse events (Fig. 3a). The ${ }^{13} \mathrm{C}$ NMR spectra of contaminated heparin lots also contained signals at $25.6 \mathrm{ppm}$ and $53.5 \mathrm{ppm}$ indicative of an $O$-substituted $N$ acetylgalactosamine moiety of unknown origin that was distinctly different from DS (Fig. $3 b$ ). The ${ }^{13} \mathrm{C}$ signals in the range 103-105 ppm suggested a $\beta$-glycosidic linkage between the monosaccharides. The results of homonuclear (COSY, TOCSY, ROESY) and heteronuclear (HSQC, HMBC) 2D NMR experiments were consistent with a structure containing a polymeric repeat of $N$-acetyl galactosamine linked to glucuronic acid. Though a preliminary identification of the contaminant was possible by NMR, conclusive assignment was achieved only after the enzymatic depolymerization of heparin and DS followed by the subsequent isolation of the intact OSCS polysaccharide. Parallel to the enrichment of the contaminant by enzymatic degradation, alcohol-based selective precipitation and chromatographic separations were also used to purify the contaminant. Taken together, the results unequivocally proved the structure of OSCS as a polymer of the unusual tetrasulfonated disaccharide composed of 2,3-O-sulfoglucuronic acid and 4,6-Osulfo- $N$-acetylgalactosamine with a 1,3 linkage between the two sugars and 1,4 linkage between adjacent disaccharide units. Because OSCS is a semisynthetic polysaccharide, direct comparison of the NMR spectra of the isolated material with a synthesized OSCS standard confirmed the identity of the contaminant [1, 6, 27, 29].

Shortly after the structural studies, a biological investigation was initiated in late March 2008 to find the missing link between OSCS and the adverse reactions. The high charge density of OSCS resulted in strong anti-factor IIa activity, allowing the contaminated sample lots to pass through the anticoagulation potency screens that were used to determine heparin efficacy and purity. Highly charged
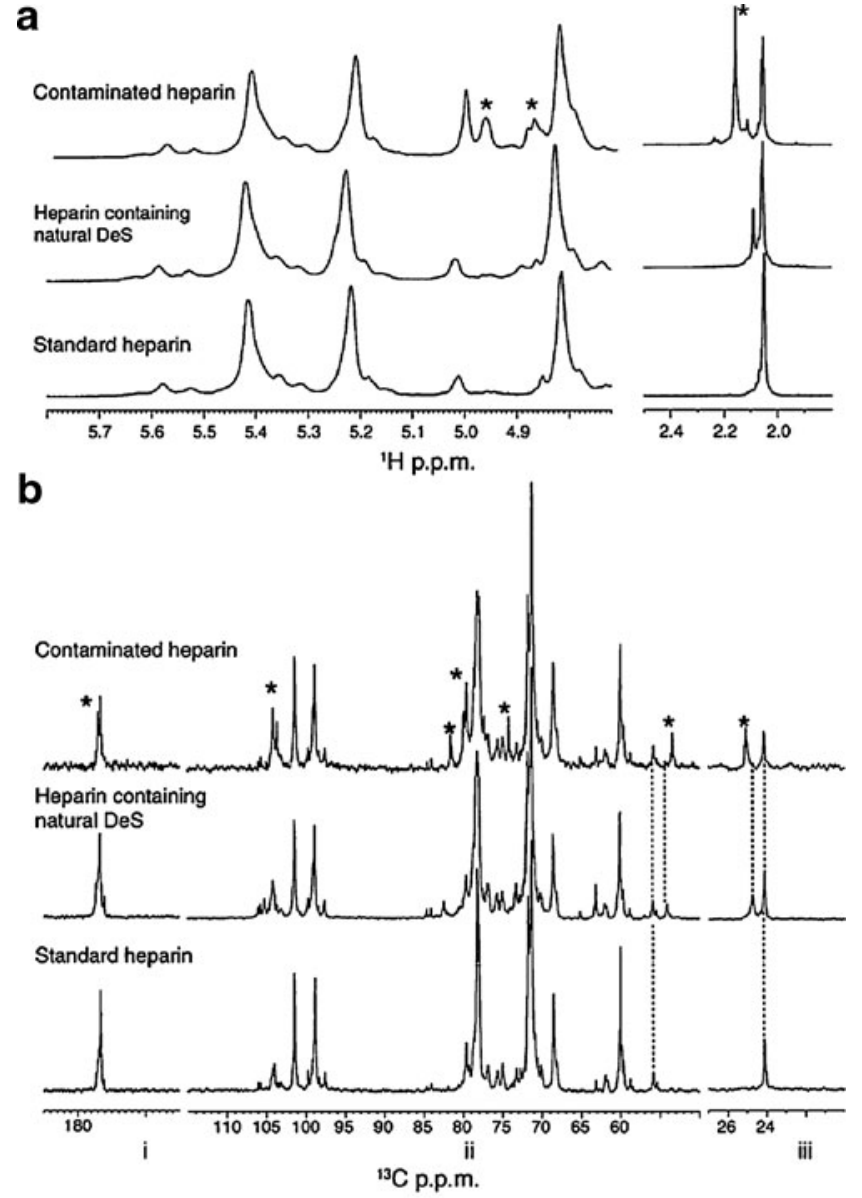

C

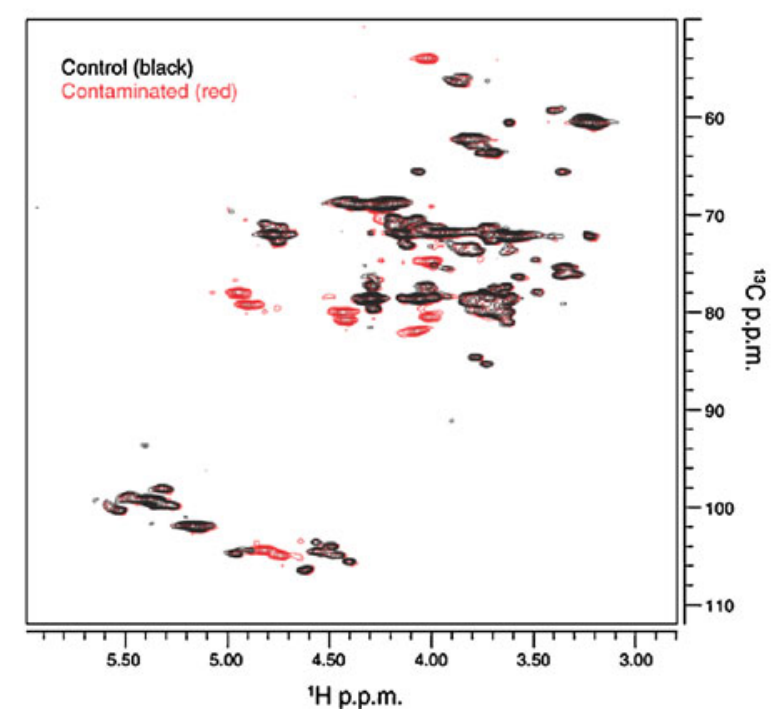

Fig. 3 NMR spectra of contaminated heparin. a Comparison of anomeric and acetyl regions of the ${ }^{1} \mathrm{H}$ NMR spectra of standard heparin, heparin containing natural dermatan sulfate (DS), and contaminated heparin. b Comparison of the carbonyl (i), sugar (ii) and $N$-acetyl (iii) regions of the ${ }^{13} \mathrm{C}$ NMR spectra of standard heparin, heparin containing natural dermatan sulfate, and contaminated heparin. Signals due to the contaminant are highlighted by asterisks. c HSQC spectrum of the contaminated sample overlaid on that of a control heparin sample. Reprinted from [1] with permission from Macmillian, copyright 2008 
anionic polysaccharides similar to heparin and OSCS have also been shown to be potent mediators of the immune response system, which may explain the severe anaphylactic response observed upon administration of the contaminated heparin $[2,6]$. A study to determine the biological link between the presence of OSCS in heparin and anaphylactic events established that concentrations of 2.5 and $25 \mu \mathrm{g} / \mathrm{mL}$ of OSCS in heparin activated the kininkallikrein pathway and its complement pathways through the fluid-phase activation of FXII in the coagulation pathway [3]. Kinin-kallikrein pathway activation results in the formation of bradykinin peptides. A strong correlation has been reported between the OSCS concentration in the contaminated heparin and the released bradykinin concentration [30], which is responsible for the enlargement of blood vessels and the subsequent drop in blood pressure.

Identification of OSCS paved the way for the establishment of authentic standards and analytical protocols to guard against future problems resulting from heparin contamination by this substance. With the introduction of an OSCS standard, NMR, HPLC, and CE methods were quickly developed to screen heparin lots in order to prevent further exposure of patients to contaminated heparin [31]. To ensure the safety of the heparin supply chain, the FDA has recommended the further development of additional physicochemical methods for the analysis of heparin purity [32].

\section{New analytical methods for heparin impurity analysis}

The health crisis created by the intentional adulteration of heparin stimulated the analytical chemistry community to rapidly introduce a number of new analytical methods for heparin impurity analysis. Work in this area continues, and this special issue contains several innovative new developments and applications that further advance the methods available for the identification and characterization of heparin impurities.

Heparin belongs to one of the most challenging groups of pharmaceutical agents to analyze and characterize. Compared to a small drug molecule, the molecular properties of pharmaceutical heparin have traditionally been pushed into the background due to its extremely complex, polydisperse and microheterogeneous structure. Structural studies on heparin at the molecular level usually begin with depolymerization of the raw/pharmaceutical material into smaller oligosaccharide fragments using enzymatic or chemical methods [33, 34]. The enzymatic depolymerization of heparin can be achieved by heparin lyases (classes I, II and III) produced by Flavobacterium heparinum [35]. Each class has a different substrate specificity with respect to the uronic acid moiety and sulfonation pattern recognized, but in all cases the cleavage of the glycosidic linkage between the glucosamine and uronic acid residues is accomplished through $\beta$-elimination. This step generates a double bond between the C-4 and C-5 positions of the uronate residue, allowing UV detection of the generated fragments at $232 \mathrm{~nm}$ with an approximate molar absorption coefficient of $5500 \mathrm{M}^{-1} \mathrm{~cm}^{-1}$ [36]. In chemical reactions that are used to convert heparin to smaller oligosaccharides, either the oxidative instability of the polymer is utilized or the enzymatic reaction is mimicked chemically [22]. The main scope of chemical depolymerization is the preparation of LMWHs.

The activity of pharmaceutical heparin is specified by clotting-time assays in the pharmacopoeias. Since OSCS exhibits anticoagulation activity [27], contaminated heparin samples passed the whole-blood coagulation screens performed by the manufacturer. Although the bio- and physicochemical behavior of OSCS is similar to that of heparin in many ways, there are differences that can be used to discriminate the impurity from the parent drug. Previous studies have shown that OSCS is resistant to heparin lyase degradation [24], which was utilized in a bioassay developed by Tami et al. [37]. The activity of the thermostable DNA polymerase from Thermus aquaticus was used in real-time PCR to detect changes in gene expression inhibited by heparin [38] which can be overcome by heparinase enzymes [39]. Because OSCS blocks polymerase-mediated cDNA amplification in a manner similar to heparin, a sensitive screening method was developed to evaluate OSCS contamination [37]. This method requires as little as $0.6 \mu \mathrm{g}$ of sample, so it may be a viable option for screening mass-limited samples such as heparin-coated devices. A correlation was found between the degree of sulfonation and the inhibitory effect of other possible oversulfated GAGs impurities (e.g., oversulfated heparan sulfate, OSHS, and oversulfated dermatan sulfate, OSDS), which can promote further application of this technique. A commercially available heparin enzyme immunoassay kit can also be used to distinguish highly sulfated GAGs (including oversulfated heparin) and normal heparin [40]. The recognition element used in this kit is an engineered protein showing 100-fold selectivity in binding to heparin over other GAGs [41]. Although electrostatic interactions between the polybasic binding site of the protein and heparin contribute only $28 \%$ of the total binding, competing GAGs with higher charge density bind to the protein with up to fourfold higher affinities than heparin. This inexpensive method, initially developed for the clinical determination of heparin levels in human plasma, provides a simple tool that can be used in earlystage production settings for impurity quantitation. There are several other assays for the quantification of heparin 
and other sulfonated biopolymers, but they are not able to differentiate components that are present in mixtures unless additional treatments are applied prior to analysis [42].

In the rapidly growing area of chemical/molecular sensor development, various novel reporter molecules have been introduced as heparin sensors [43, 44]. In these applications the sensory effect is based on charge interactions, so their specificity is limited. Among the biosensors, potentiometric detection of polyanionic species (such as OSCS) has been achieved using modified polymer membranes with anionexchange capacity [45]. As with previous methods, this simple approach gives a reproducible response to highly charged impurities. Since the initial report of this biosensor, additional studies have been performed to clarify the quantitation procedure [46].

To ensure the identity and quality of critical drugs such as heparin, orthogonal and complementary methods to those employed in the pharmacopoeia should also be applied, including NMR, Raman, and near-infrared spectroscopy (NIR) [4, 47]. An advantage of both NIR and Raman spectroscopy is that they can be used to characterize solid heparin samples and detect OSCS contamination above $1 \%$ [48]. A nondestructive NIR method has been extended beyond impurity analysis as a potential tool for heparin potency determination [49].

Efforts are also being made to develop quick and cheap thin layer chromatography (TLC) methods to characterize GAGs [50]. It has been shown recently that TLC can be used to determine the size and purity of GAG-derived oligosaccharides, to analyze the activities of polysaccharide lyases acting on GAGs, and to monitor the preparation of GAG-derived oligosaccharides [51]. At the current time, this method is only able to separate oligosaccharides bearing low net charges.

\section{NMR spectroscopy}

NMR played a decisive role in the structure determination of OSCS during the heparin crisis, although the exceptionally high concentration of OSCS in the adulterated samples likely contributed to its successful identification by this method. The complete ${ }^{1} \mathrm{H}$ NMR assignment of OSCS has been reported in several recent publications [1, 31, 52, 53] and in the original work by Maruyama et al. [27]. It is also important to note that Holzgrabe et al. published ${ }^{1} \mathrm{H}$ NMR spectra of heparin in 1998 which already contained the resonances of OSCS [54]. In addition to the ${ }^{1} \mathrm{H}$ and ${ }^{13} \mathrm{C}$ NMR spectra, the heteronuclear HSQC and HMBC experiments were important for the conclusive molecular level characterization of OSCS (Fig. 3c). Signals associated with the characteristic OSCS moieties are easily detectable in the HSQC spectrum of OSCS-contaminated heparin (Fig. 4).

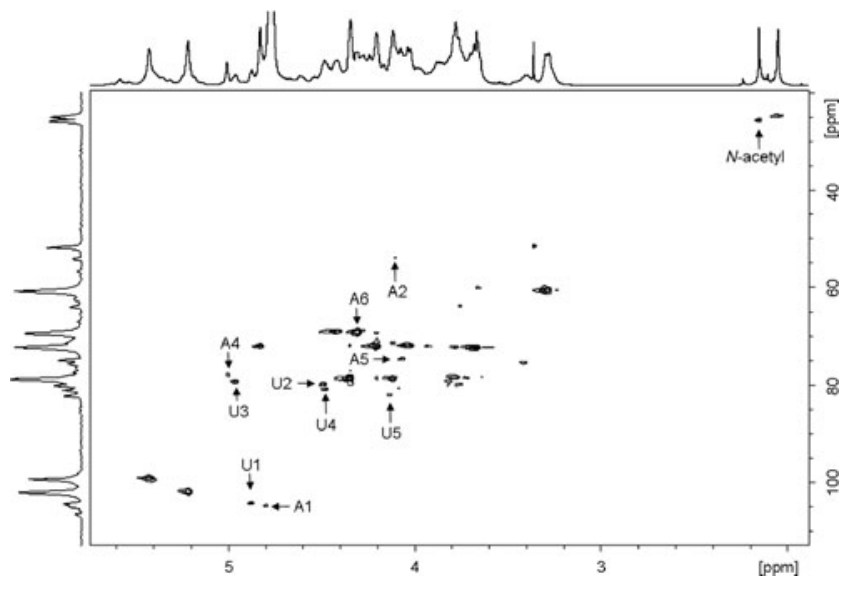

Fig. 4 HSQC spectrum of heparin containing $10 \%$ (w/w) OSCS prepared using a $20 \mathrm{mg} / \mathrm{mL} \mathrm{D}_{2} \mathrm{O}$ solution of the USP system suitability standard at pD 6.6 and $298.2 \mathrm{~K}$. To improve the line shape, $1 \%$ EDTA- $d_{16}$ was added. The spectrum was acquired using 32 scans per increment with 2560 and 512 data points in F2 and F1, respectively, using a $600 \mathrm{MHz}$ NMR equipped with a broadband inverse probe. The polarization transfer delay was set using a ${ }^{1} J_{\mathrm{C}-\mathrm{H}}$ coupling value of $155 \mathrm{~Hz}$. The spectrum was referenced to internal TMSP. The characteristic OSCS signals for GalNAc4S6S and GlcA2S3S are labeled as $A$ and $U$ respectively

Due to its high sensitivity to even minor structural variations, ${ }^{1} \mathrm{H}$ NMR spectroscopy has been used previously to detect variations in the chemical composition of heparin $[25,55,56]$, low molecular weight heparins [57], heparinderived oligosaccharides $[58,59]$ and as a screening tool for GAG impurities $[25,60]$. As ${ }^{1} \mathrm{H}$ NMR has also been recommended by the FDA as one of the analytical techniques for rapidly screening OSCS, intense efforts are being made to improve the NMR-based characterization of heparin API. To obtain a satisfactory NMR spectrum for correct identification, several factors should be considered. As demonstrated previously, the chemical shift of the OSCS $\mathrm{N}$-acetyl methyl signal is counterion type and concentration dependent; it varies linearly from $2.13 \mathrm{ppm}$ to $2.18 \mathrm{ppm}$ with increasing amounts of $\mathrm{Ca}^{2+}$ until reaching a saturation point of four $\mathrm{Ca}^{2+}$ per tetrasulfonated disaccharide unit [61]. Paramagnetic transition metal ions, present as production residuals, can cause line broadening through paramagnetic relaxation enhancement, even within the range of allowed quantities [62]. Especially $\mathrm{Mn}^{2+}$ was found to present the most pronounced effect on the heparin iduronic acid H1 (5.22 ppm) and H5 (5.42 ppm) protons and the OSCS methyl protons, the crucial signal for OSCS quantification. Filtering the solution through a cation exchange resin prior to measurement or adding $300 \mu \mathrm{g}$ EDTA per gram of heparin can eliminate the unwanted broadening [62].

Acquiring spectra at elevated temperatures can improve the ${ }^{1} \mathrm{H}$ resonance line shape of GAG solutions [63]. 
Measuring spectra at $333 \mathrm{~K}$ (or even $353 \mathrm{~K}$ ) enables clear isolation of the $\mathrm{H} 5$ proton of the sulfonated iduronic acid residue from other proton signals in the fingerprint region, including the water/HDO resonance due to its temperatureinduced upfield shift [64]. Caution should be applied when taking measurements using unbuffered heparin solutions, which can result in $\mathrm{pH}$-dependent chemical shift differences for the carboxylate-adjacent $\mathrm{H} 5$ proton of the uronic acid residue [53].

Low-level contaminant peaks can be masked by the heparin ${ }^{13} \mathrm{C}$ satellite peaks, and in these cases ${ }^{13} \mathrm{C}$ decoupling is recommended to discriminate the satellite peak from the contaminant [65]. Although it can be difficult to detect certain GAG impurity signals by visual inspection of the ${ }^{1} \mathrm{H}$ survey spectrum, multidimensional NMR can easily detect and distinguish between analogous sulfonated polysaccharides [66]. To obtain more contaminant-specific signals from the crowded fingerprint region and improve the reliability of impurity identification, 2D NOESY can provide a highly informative ${ }^{1} \mathrm{H}$ fingerprint [67].

The accurate quantification of ${ }^{1} \mathrm{H}$ NMR signals requires a high-quality spectrum, which can typically be achieved using a high magnetic field ( $\geq 500 \mathrm{MHz}$ ), optimum solution conditions, and appropriate NMR parameters [53]. Beyer and coworkers have shown that even when using 300 or $400 \mathrm{MHz}$ NMR spectrometers, the OSCS LOD can be as low as $0.1 \%$ [63] These authors analyzed over 100 heparin API samples using the standard addition method and monitoring the $N$-acetyl region. They developed a routine ${ }^{1} \mathrm{H}$ NMR-based screening for heparin API, quantified both OSCS and DS, and proved the lack of correlation between these signals. In addition to quantifying OSCS and DS, Beyer et al. also reported other impurities that are present in varying amounts in pharmaceutical heparin, including methanol, ethanol and acetate [63]. In a subsequent study, this group also scrutinized the German heparin market and analyzed 145 representative samples from 2008 [68]. The samples tested by ${ }^{1} \mathrm{H}$ NMR were found to contain DS (51\%) and OSCS (19\%), as well as process-related impurities such as ethanol, methanol, acetone, formic acid and acetate in considerable amounts. As these process impurities remain undetectable by CE and LC methods, it is anticipated that NMR may be more widely exploited in future pharmacopoeias. Keire et al. have also reported a $0.1 \%$ LOD for OSCS on a $500 \mathrm{MHz}$ instrument using $25 \mathrm{mg} / 700 \mu \mathrm{L}$ heparin solutions [69]. This group has also identified additional native and oversulfated GAGs as possible economically motivated adulterants based on their characteristic chemical shifts in the $N$-acetyl and 3.0 $6.0 \mathrm{ppm}$ region [70]. CSA, DS, OSCS and OSDS showed unique signal patterns when spiking the heparin sample, while HS, OSHS and oversulfated heparin were found to be difficult to identify [70].
Diffusion NMR experiments correlate the rate of decay of NMR resonances with their translational diffusion coefficients, which are related to molecular properties such as size, shape, and charge. Diffusion NMR can be a very useful method for mixture analysis, often allowing the noninvasive separation of resonances due to different mixture components [71]. The first report that employed diffusion NMR to characterize heparin solutions, from Kellenbach and coworkers [72], used pulsed-field gradient longitudinal encode-decode (PFG-LED) experiments to identify signals of low molecular weight impurities in a synthetic heparin pentasaccharide solution. Because of the large difference in size between the synthetic heparin pentasaccharide and its impurities, simple "gradient on/ off" experiments were capable of discriminating between the components in the synthesis solution.

Shortly following the identification of OSCS as the heparin adulterant, Sitkowski and coworkers investigated the utility of DOSY NMR as a routine screening method for OSCS in LMW and unfractionated heparin [73]. DOSY is a pseudo-2D NMR experiment that correlates the calculated diffusion coefficient with the NMR chemical shift. Because the chemical shifts of the $N$-acetyl resonances of heparin, DS, and OSCS are well resolved, the DOSY plots obtained by Sitkowski et al. could resolve the diffusion coefficients of OSCS and DS from both LMW and unfractionated heparin. They also observed that in mixtures containing both LMW and unfractionated heparin, the components could not be resolved on the basis of diffusion, and the diffusion coefficient measured for heparin was a weighted average of both components. In a recent study by the same group, diffusion NMR was used for the separation and characterization of contaminants in pharmaceutical heparin [74]. These authors noted resonances of currently unidentified contaminants which produced diffusion coefficients that were different from those observed for heparin, DS, and OSCS.

In addition to the contamination of heparin with OSCS and DS, the chemical modification of heparin during the manufacturing process could be another source of heparin impurities, such as those introduced by $O$-acetylation [4]. Such impurities are likely to be present at low levels and can be challenging to identify due to their structural similarity to heparin. A novel heteronuclear NMR experiment, HEHAHA, introduced by Jones and Bendiak [75], has been used to characterize the primary structures of oligosaccharides as well as to determine positions of modification. This experiment uses doubly ${ }^{13} \mathrm{C}$-labeled acetyl groups to establish correlations between protons on the sugar rings and $O$-acetyl moieties. A selective version of this experiment, SHEHAHA, accomplishes magnetization transfer between the carbonyl ${ }^{13} \mathrm{C}$ and the proximal proton on the sugar ring while suppressing proton-proton 
TOCSY relay to the other sugar ring protons, allowing assignment of the location of the $O$-acetyl group $[75,76]$.

\section{Electrophoretic methods}

Polyacrylamide gel electrophoresis (PAGE)

Fractionation of highly charged macromolecules generally requires successive use of several separation steps, one sensitive primarily to molecular size, and another based mainly on net charge. PAGE provides a versatile method for the separation and physicochemical characterization of molecules by exploiting differences in size, conformation and charge [77]. The utility of this technique in GAG oligosaccharide sequencing has been demonstrated [78-80]. For oligosaccharide purification and isolation, native PAGE has been used, but the recovery of the separated components on the micropreparative scale was difficult, and the purity of the isolated sample was insufficient for structural studies by NMR and MS [81]. In contrast, native continuous elution PAGE provides high-resolution separation of GAG-derived oligosaccharides over a large molecular weight range, and the gel-eluted oligosaccharides are amenable to structural characterization [82]. As a complementary screening technique to ${ }^{1} \mathrm{H}$ NMR, PAGE was utilized in a comprehensive analysis of 31 heparin samples prepared from 1941 through 2008 [83]. Nitrous acid depolymerization of the heparin API followed by PAGE analysis gave LOD values for heparin impurities ranging from 0.1 to $5 \%$.

PAGE was also used to characterize the sensitivity of OSCS to different depolymerization processes used in LMWH production [24]. On the basis of this analysis, OSCS was found to be sensitive to base-catalyzed $\beta$ eliminative cleavage and $\mathrm{H}_{2} \mathrm{O}_{2}$ treatment. Oxidative depolymerization by $\mathrm{H}_{2} \mathrm{O}_{2}$ converted OSCS to monosaccharides at $\mathrm{pH} 2$ (a more efficient depolymerization compared to heparin), while longer oligosaccharides were observed at $\mathrm{pH} 5$ and $\mathrm{pH}$ 7. The oversulfated impurity was resistant to heparin lyase I treatment, and due to its structural features both nitrous acid (due to the lack of a nitrous acid sensitive $N$-sulfo group) and periodate (due to lack of a vicinal diol moiety) failed to degrade OSCS [24]. PAGE analysis of OSCS-contaminated low molecular weight heparins successfully detected OSCS among other possible impurities following nitrous acid treatment.

\section{Capillary electrophoresis (CE)}

Given the polyanionic nature of GAGs, capillary electrophoresis is one of the best separation techniques to analyze highly charged polysaccharides [84]. The advantages of CE methods over other chromatographic approaches are the high number of theoretical plates, rapid analysis time, and low sample consumption. Compared to liquid chromatographic methods, no organic solvents or additives are necessary, so this method is more environmentally friendly. The possibility of on-line coupling with MS $[84,85]$ and NMR as detectors gives the potential to obtain unique structural information. As crude GAG polymers lack strong UV chromophores, it is difficult to detect them directly by UV measurements. Indirect detection of GAGs in CE overcomes this limitation, but it can be difficult to find a suitable background electrolyte which meets all of the necessary criteria [86]. Depending on the approach used, the controlled degradation of the GAG biopolymers can also improve their detection. For example, enzymatic depolymerization or chemical degradation under alkaline conditions introduces a chromophore that allows sensitive UV detection and quantitative determination. Alternatively, the oligosaccharides can be chemically derivatized, mainly at the reducing end of the sugar, converting them to analytes suitable for UV or the more sensitive fluorescence detection.

The electrophoretic behavior of heparin-derived oligoand disaccharides has been intensively studied for the past two decades, with the first CE application for both intact and depolymerized GAGs reported in the 1990s [87, 88]. Among the first steps in the evolution of CE methods was the recognition of the advantage of acidic buffers over the previously applied basic, SDS-containing background electrolytes [89] and the resolving power of reversedpolarity separations [90]. In the case of reversed polarity, the sample is introduced at the negative end of the capillary and migrates in the opposite direction to the electroosmotic flow (EOF). At low $\mathrm{pH}$, the EOF is naturally low, and as phosphate buffer is well known to coat the capillary surface [91], good reproducibility of migration times is obtained through well-controlled EOF. The $\mathrm{pH}$ selected for reversed polarity $\mathrm{CE}$ separations of GAG-derived compounds is typically around 3.5-4, near the $\mathrm{p} K_{\mathrm{a}}$ values of the uronic acid carboxylate groups. The differential effective charge resulting from the subtle effects of structure on carboxylic acid $\mathrm{p} K_{\mathrm{a}}$ values allows the resolution of oligosaccharides which would otherwise have very similar migration times [92]. Further developments aimed at improving the sensitivity of detection using laser-induced fluorescence [93] and electrospray ion trap mass spectrometry [94] have been reported. For low molecular weight heparins, CE offers the possibility of fingerprinting these biopolymer mixtures, which is especially useful for assessing product identity, quality and variability [95].

Since the OSCS adulteration event, there has been growing interest in $\mathrm{CE}$ applications for the rapid screening of heparin, as capillary electrophoresis is one of the techniques recommended by the FDA. The intense effort 
to identify OSCS in contaminated samples led to a robust, validated $\mathrm{CE}$ method which was quickly incorporated into the USP monograph. The basis for this initial CE separation were previously reported phosphate buffer-based reversedpolarity methods [96, 97]. This so-called "emergency method," in conjunction with NMR, helped to identify and remove suspect heparin lots from the market. However, the downside of the emergency CE method is its relatively high LOD for OSCS, estimated at between 1 and $5 \%$ of total heparin, far from the expected $0.1 \%$. Also, as shown in Fig. 5a, only partial separation of OSCS and heparin could be achieved; the contaminant appeared as a leading edge
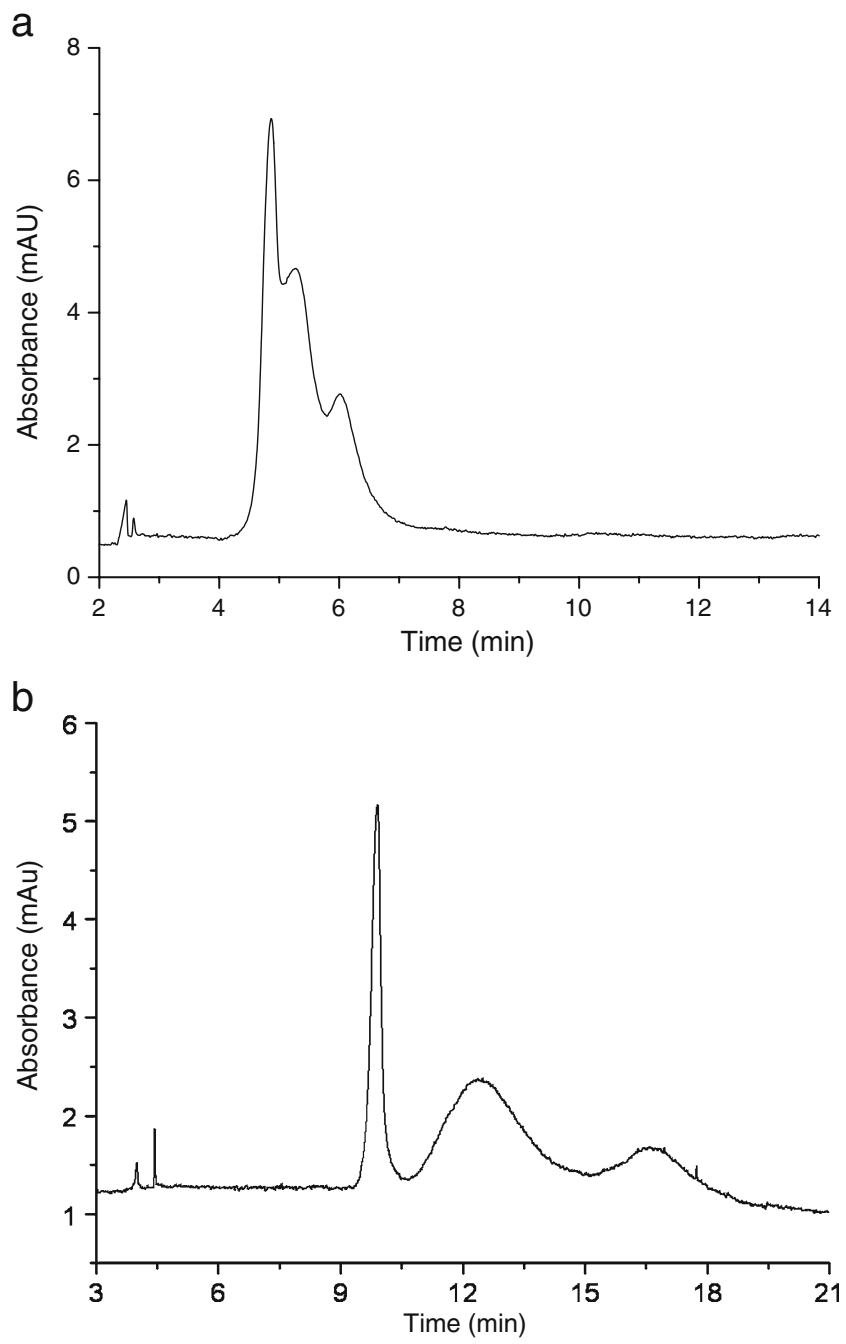

Fig. 5 a CE-UV electropherogram of OSCS-contaminated heparin $(10 \mathrm{mg} / \mathrm{ml})$ using the FDA emergency method. $(50 \mu \mathrm{m}$ capillary I.D., $36 \mathrm{mM}$ sodium phosphate $\mathrm{pH} 3.5 \mathrm{BGE}$, capillary temperature $25^{\circ} \mathrm{C}$, $12 \mathrm{~s}$ sample injection at $0.5 \mathrm{psi} ;-30 \mathrm{kV}$ voltage.) The unresolved peaks are OSCS, heparin and DS, respectively, according to their decreasing mobility. b CE-UV of OSCS-contaminated heparin $(10 \mathrm{mg} /$ $\mathrm{ml})$ using the optimized method. $(25 \mu \mathrm{m}$ capillary I.D., $850 \mathrm{mM}$ Tris phosphate $\mathrm{pH} 3.0 \mathrm{BGE}, 60 \mathrm{~cm}$ total capillary length, capillary temperature $35{ }^{\circ} \mathrm{C}, 24 \mathrm{~s}$ sample injection at $2.0 \mathrm{psi} ;-30 \mathrm{kV}$ voltage.) Reprinted from [99] with permission from Elsevier peak that was only partially resolved from the broad peak associated with heparin. In order to reach the desired low limit of detection and separation resolution, and to extend the method to other possible impurities such as DS and heparan sulfate, Wielgos and coworkers have optimized and improved the CE separation protocol [98]. Although this method fulfills all the necessary criteria for a sensitive, selective, robust and reproducible separation method, as illustrated by the electropherograms shown in Fig. 6, the capillary used in this separation fits only the Agilent CE instrument. Shortly after this publication, a similar simple methodology appeared demonstrating the applicability of the method on generic CE equipment [99]. Method development in both cases started with the USP-adapted version of the FDA method using a $50 \mu \mathrm{m}$ I.D. capillary and $36 \mathrm{mM}$ phosphate buffer ( $\mathrm{pH} 3.5)$.

In this system, the migration order of the GAG components is determined largely by their charge; OSCS has the fastest migration, followed by heparin, with the least-charged component, dermatan sulfate, migrating most slowly, as shown in Fig. 5a. During the optimization of these $\mathrm{CE}$ methods, the concentration of the background electrolyte (BGE) was found to be crucial to an effective separation. Increasing buffer concentration relative to that used in the initial USP emergency method led to the following improvements: (i) better sample stacking and sharpening of the OSCS peak as a result of the larger difference in conductivity between the running buffer and the analyte; (ii) improved resolution; (iii) higher current and Joule-heating effects which required the use of smaller $(25 \mu \mathrm{m})$ I.D. capillaries; (iv) application of BGEs below $\mathrm{pH}$ 3.5, and; (v) injection of large sample volumes of concentrated samples, which allowed these methods to reach a reasonably low LOD $(0.05 \%$ or even less $)$ for OSCS (Figs. 5b and 6). A crucial parameter to allow highmolarity buffers and achieve full separation is the replacement of sodium ions by lithium [98] or Tris [99], as these ions contribute less to the BGE conductance but still provide the same ionic strength. There are certainly other parameters besides the aforementioned ones that influenced the separation (such as the applied voltage, capillary length and temperature, injection parameters), but their optimum values are predominantly empirically determined.

The main advantage of $\mathrm{CE}$ for heparin impurity analyses is the rapid analysis time, allowing high-throughput screening of the QC samples. Using a shortened capillary and replacing sodium ions by the lower mobility lithium led to a much shorter and better separation, with a LOD well below $0.1 \%$ [98], as can be seen in Fig. 6. Another innovative approach is the anthranilic acid (AA) derivatization and CE separation of the GalN and GlcN hexosamines of OSCS and heparin, respectively, following acidic hydrolysis [100]. An advantage of this approach is that the 


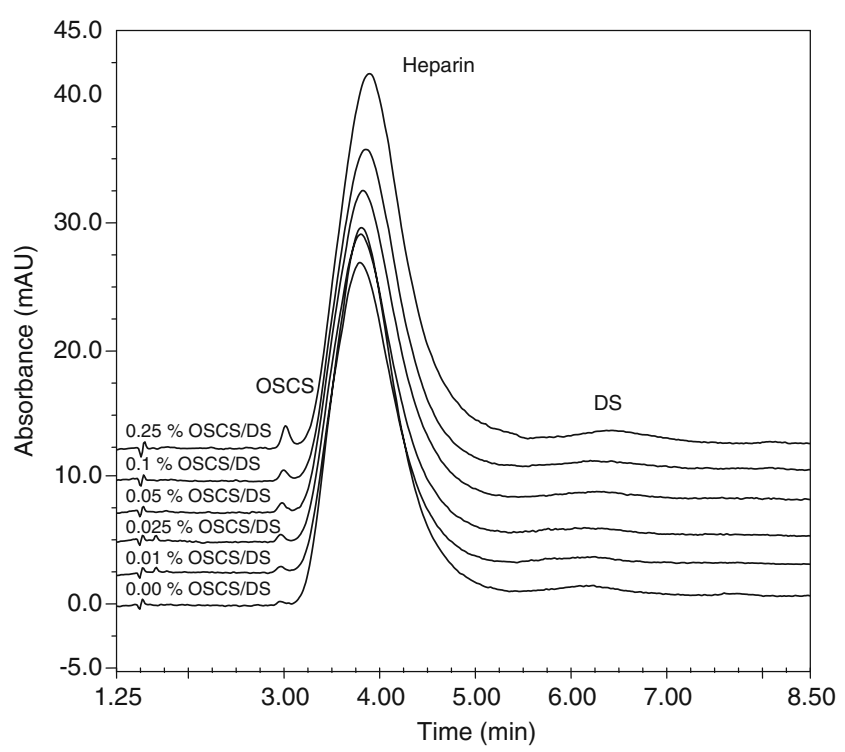

Fig. 6 High-speed CE separation of heparin, OSCS and DS. $(25 \mu \mathrm{m}$ capillary I.D., $600 \mathrm{mM}$ lithium phosphate $\mathrm{pH} 2.8 \mathrm{BGE}$, temperature $20{ }^{\circ} \mathrm{C}, 600 \mathrm{mbs}$ injection and $-14 \mathrm{kV}$ voltage.) Reprinted from [98] with permission from Elsevier

AA derivatives have similar molar absorptivities, allowing direct quantitation from the electropherogram. The urgent need for but lack of an appropriate CE method for heparin impurity analysis in the pharmacopoeias evokes further method refinements [101], but even with these limitations CE has become an alternative method to NMR for reliable heparin quality assurance.

\section{Chromatography and hyphenated techniques}

This section discusses chromatographic methods developed for the analysis of the heparin impurities OSCS and DS. A detailed discussion of the application of chromatographic separations for heparin structural characterization is beyond the scope of this paper, and has been recently reviewed [5]. HPLC is the most prevalent technique in analytical laboratories and is frequently used in pharmacopoeial monographs. A broad range of HPLC techniques are available for heparin analysis, the majority of which utilize anion-exchange or reversed-phase ion-pair separations. Strong anion-exchange (SAX) HPLC methods have been used for the isolation, purification and oligosaccharide mapping of depolymerized heparin [102-104]. The separation of oligosaccharide species by charge using salt gradient elution is convenient and easy to perform, so SAX-HPLC is a plausible technique for heparin impurity analysis. Silica-based SAX columns with quaternary ammonium groups were shown to be unsuitable for persistent application due to poor stability and retention time reproducibility [31, 102]. Therefore, Trehy et al. used a polymeric SAX column for heparin impurity separations [31]. Using a linear gradient from $0.125 \mathrm{M}$ to $2.5 \mathrm{M} \mathrm{NaCl}$ in $\mathrm{pH} 3$ buffered mobile phase at $35^{\circ} \mathrm{C}$, UV detection at $215 \mathrm{~nm}$ and a constant $0.8 \mathrm{~mL} / \mathrm{min}$ flow rate, this SAX separation gave LODs for OSCS and DS of $0.03 \%$ and $0.1 \%$, respectively. A slight modification of the sample preparation protocol, dissolving $100 \mathrm{mg}$ sample in $1 \mathrm{~mL}$ of the $2.5 \mathrm{M} \mathrm{NaCl}$ eluent buffer, gave an even better LOD $(0.02 \%)$ and LOQ $(0.09 \%)$ for OSCS [69]. This SAX-HPLC method is a more sensitive method of detecting OSCS in crude heparin than NMR and is also able to separate heparin from other contaminants such as HS, DS, their oversulfated derivatives (e.g., OSHS, OSDS) as well as oversulfated heparin (OSH) [70].

Weak anion-exchange (WAX) HPLC methods have also been reported for OSCS $[105,106]$. Hashii et al. showed that replacement of $\mathrm{NaCl}$ in the elution buffer with alkali perchlorates resulted in better peak symmetry and less baseline drift using UV detection, producing an LOD for OSCS that was comparable with the previously described SAX method [106]. Because of the important role played by NMR spectroscopy in the identification of OSCS as a heparin contaminant, our group explored the use of WAX HPLC-NMR for the separation and identification of heparin and its impurities DS, CSA, and OSCS [105]. Using WAX chromatography, the intact GAGs were separated using a salt gradient from $0.1 \mathrm{M}$ to $1.0 \mathrm{M} \mathrm{NaCl}$ at a solution $\mathrm{pD}$ of 10.25 with UV detection at $215 \mathrm{~nm}$ and on-flow ${ }^{1} \mathrm{H}$ NMR. Figure 7 shows the UV chromatogram (A) and on-flow NMR spectrum (B) for the separation of heparin and OSCS.

Although the on-flow NMR spectra are noisy, stop-flow HPLC-NMR can be used to improve the $\mathrm{S} / \mathrm{N}$ of the spectra and for 2D NMR experiments, which are often necessary for contaminant identification. We also demonstrated that by holding the $\mathrm{NaCl}$ concentration below $0.8 \mathrm{M}$, OSCS can be near-quantitatively trapped on the WAX column while heparin is directed to waste, allowing on-column concentration through multiple injections. Peak trapping of OSCS provided a route to the on-line concentration of the contaminant, presenting a more concentrated sample for ${ }^{1} \mathrm{H}$ NMR identification and structural characterization. This work demonstrates that when unexpected peaks are encountered in the routine screening of samples by LCUV, WAX-NMR can be exploited for the rapid identification and structural elucidation of new or novel impurities.

Size-exclusion chromatography (SEC) can also be used to detect and quantify OSCS in contaminated samples. Due to its resistance to heparinase I digestion, OSCS contaminants remain intact after depolymerization of unfractionated heparin and enoxaparin samples [52]. SEC results indicated that the mean molecular weight of OSCS in recalled heparin batches was $16.8 \mathrm{kDa}$ [52].

Reversed-phase ion-pair (RPIP) HPLC is a promising and increasingly popular method for the separation of heparin 


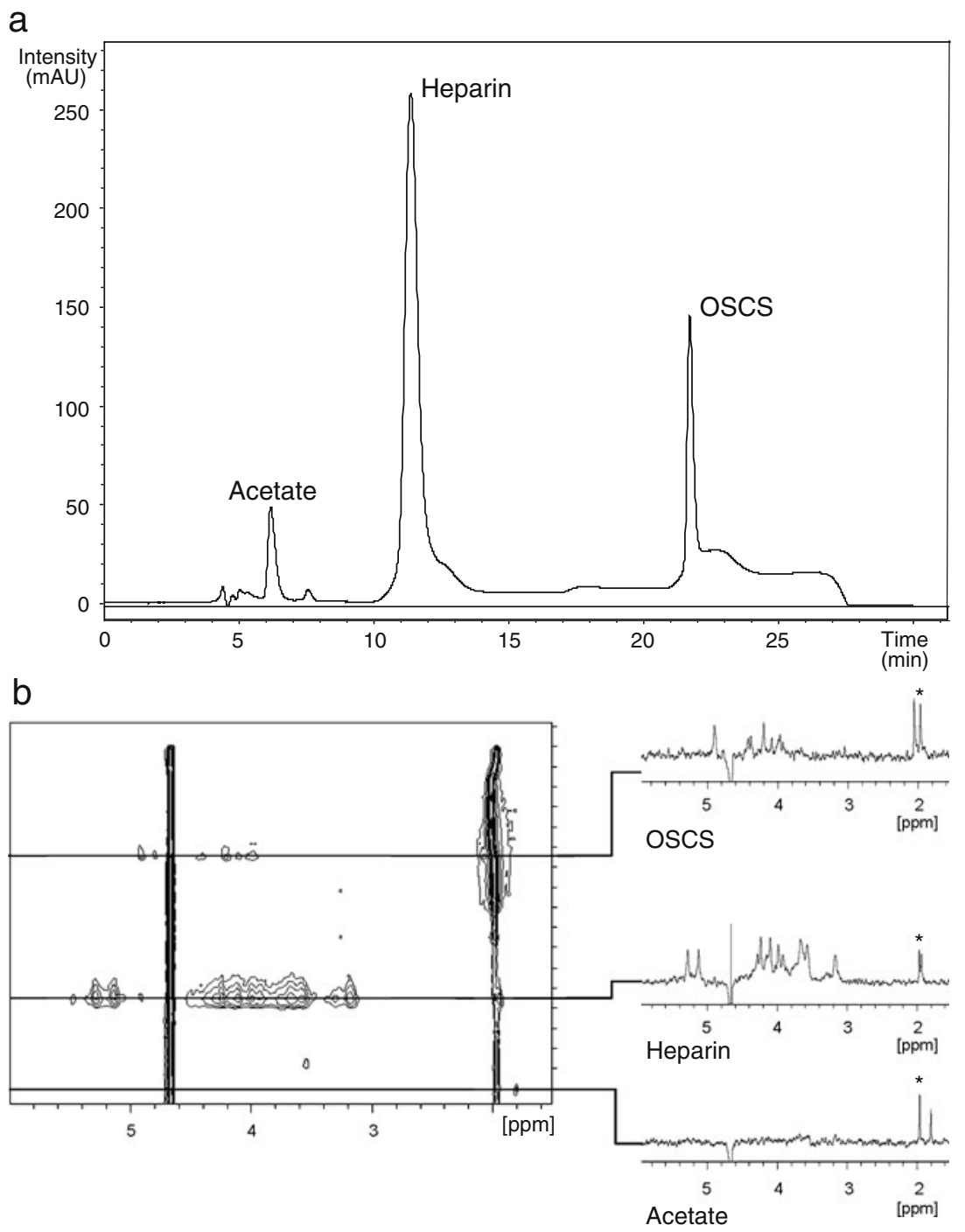

Fig. 7 Weak anion exchange separation of a $40 \mathrm{mg} / \mathrm{mL}$ heparin and OSCS sample using the Asahipak NH2P50E amino-bonded column with UV (a) and on-flow ${ }^{1}$ H NMR (b) detection. Reprinted from [105] with permission from the American Chemical Society, copyright 2009

oligosaccharides [107, 108]. Several studies have demonstrated the amenability of RPIP-HPLC and UPLC to on-line MS detection, greatly improving the sensitivity and amount of structural information that can be obtained [109-112]. Following heparinase cocktail digestion of control and OSCS-contaminated heparin samples, RPIP-HPLC was used to record chromatograms for which the heparin di-, tri-, and tetrasaccharide peaks were integrated. The contaminated samples contained significantly reduced peak areas compared with the controls, indicating that the contaminant was heparinase resistant, and aiding its identification as OSCS [1].

\section{Future prospects}

Prompted by the need to identify OSCS in contaminated heparin lots, a wealth of analytical methods have been developed for the quality assurance and rapid identification of contaminants in unfractionated and LMW heparin. Heparin is among the few remaining pharmaceutical agents isolated from animal sources, which along with its inherent heterogeneity contributes to challenges in quality assurance. Although a synthetic heparin pentasaccharide - fondaparinux - is currently available, its market share is relatively low. Fondaparinux is used clinically for treatment of deep-vein thrombosis and pulmonary embolism, but its urinary excretion precludes its use for dialysis patients. On the horizon are higher molecular weight synthetic heparin drugs, the development of which will depend on improved synthetic methods, or alternatively bacterial expression systems that can produce effective heparin substitutes. Until reliable synthetic, semisynthetic, or bacterially expressed products are available for all clinical applications of heparin, the need for robust, efficient and sensitive analytical methods for heparin impurities will remain. 
Acknowledgements The authors gratefully acknowledge financial support from the National Science Foundation grant CHE 0848976. Sz.B. gratefully acknowledges a fellowship from the Hungarian American Enterprise Scholarship Fund and OTKA MB08A/80066. J. F.K.L. acknowledges support from a 2008-2010 U.S. Pharmacopeia graduate fellowship.

Open Access This article is distributed under the terms of the Creative Commons Attribution Noncommercial License which permits any noncommercial use, distribution, and reproduction in any medium, provided the original author(s) and source are credited.

\section{References}

1. Guerrini M, Beccati D, Shriver Z, Naggi A, Viswanathan K, Bisio A, Capila I, Lansing JC, Guglieri S, Fraser B, Al-Hakim A, Gunay NS, Zhang ZQ, Robinson L, Buhse L, Nasr M, Woodcock J, Langer R, Venkataraman G, Linhardt RJ, Casu B, Torri G, Sasisekharan R (2008) Nature Biotechnol 26:669-675

2. Blossom DB, Kallen AJ, Patel PR, Elward A, Robinson L, Gao GP, Langer R, Perkins KM, Jaeger JL, Kurkjian KM, Jones M, Schillie SF, Shehab N, Ketterer D, Venkataraman G, Kishimoto TK, Shriver Z, McMahon AW, Austen KF, Kozlowski S, Srinivasan A, Turabelidze G, Gould CV, Arduino MJ, Sasisekharan R (2008) N Engl J Med 359:2674-2684

3. Kishimoto TK, Viswanathan K, Ganguly T, Elankumaran S, Smith S, Pelzer K, Lansing JC, Sriranganathan N, Zhao GL, GalchevaGargova Z, Al-Hakim A, Bailey GS, Fraser B, Roy S, RogersCotrone T, Buhse L, Whary M, Fox J, Nasr M, Dal Pan GJ, Shriver Z, Langer RS, Venkataraman G, Austen KF, Woodcock J, Sasisekharan R (2008) N Engl J Med 358:2457-2467

4. Guerrini M, Zhang ZQ, Shriver Z, Naggi A, Masuko S, Langer R, Casu B, Linhardt RJ, Torri G, Sasisekharan R (2009) Proc Natl Acad Sci USA 106:16956-16961

5. Korir A, Larive CK (2009) Anal Bioanal Chem 393:155-169

6. Liu HY, Zhang ZQ, Linhardt RJ (2009) Nat Prod Rep 26:313321

7. Rabenstein DL (2002) Nat Prod Rep 19:312-331

8. Gatti G, Casu B, Hamer GK, Perlin AS (1979) Macromolecules 12:1001-1007

9. Whitelock JM, Iozzo RV (2005) Chem Rev 105:2745-2764

10. Gallagher JT, Walker A (1985) Biochem J 230:665-674

11. Feyerabend TB, Li J-P, Lindahl U, Rodewald H-R (2006) Nat Chem Biol 2:195-196

12. Kolset SO, Prydz K, Pejler G (2004) Biochem J 379:217-227

13. Capila I, Linhardt RJ (2002) Angew Chem Int Ed Engl 41:390 412

14. Folkman J, Weisz PB, Joullie MM, Li WW, Ewing WR (1989) Science 243:1490-1493

15. Sasisekharan R, Shriver Z, Venkataraman G, Narayanasami U (2002) Nat Rev Cancer 2:521-528

16. Tyrrell DJ, Kilfeather S, Page CP (1995) Trends Pharmacol Sci 16:198-204

17. Jorpes E (1935) Biochem J 29:1817-1830

18. Lindahl U, Bäckström G, Thunberg L, Leder IG (1980) Proc Natl Acad Sci USA 77:6551-6555

19. Björk I, Lindahl U (1982) Mol Cell Biochem 48:161-182

20. Barrowcliffe TW (1995) Brit J Haematol 90:1-7

21. Linhardt RJ (2003) J Med Chem 46:2551-2564

22. Linhardt RJ, Gunay NS (1999) Semin Thromb Hemost 25:5-16

23. Fareed J, Jeske W, Hoppensteadt D, Clarizio R, Walenga JM (1998) Am J Cardiol 82:3L-10L

24. Zhang ZQ, Weiwer M, Li BYZ, Kemp MM, Daman TH, Linhardt RJ (2008) J Med Chem 51:5498-5501
25. Neville GA, Mori F, Holme KR, Perlin AS (1989) J Pharm Sci 78:101-104

26. Trowbridge JM, Gallo RL (2002) Glycobiology 12:117R-125R

27. Maruyama T, Toida T, Imanari T, Yu G, Linhardt RJ (1998) Carbohydr Res 306:35-43

28. FDA (2008) FDA's ongoing heparin investigation. http://www. fda.gov/NewsEvents/Testimony/ucm115242.htm. Accessed 21 June 2010

29. Sasisekharan R, Shriver Z (2009) Thromb Haemost 102:854 858

30. Adam A, Montpas N, Keire D, Désormeaux A, Brown NJ, Marceau F, Westenberger B (2010) Biomaterials 31:5741-5748

31. Trehy ML, Reepmeyer JC, Kolinski RE, Westenberger BJ, Buhse LF (2009) J Pharm Biomed Anal 49:670-673

32. Leiden JM (2008) Nat Biotech 26:624-626

33. Lohse DL, Linhardt RJ (1992) J Biol Chem 267:24347-24355

34. Shively JE, Conrad HE (1976) Biochemistry 15:3932-3942

35. Galliher PM, Cooney CL, Langer R, Linhardt RJ (1981) Appl Environ Microbiol 41:360-365

36. Linker A, Hovingh P (1972) Biochemistry 11:563-568

37. Tami C, Puig M, Reepmeyer JC, Ye H, D'Avignon DA, Buhse L, Verthelyi D (2008) Biomaterials 29:4808-4814

38. Furukawa K, Bhavanandan VP (1983) Biochim Biophys Acta 740:466-475

39. Izreli S, Pfleiderer C, Lion T (1991) Nucleic Acid Res 19:6051

40. Bairstow S, McKee J, Nordhaus M, Johnson R (2009) Anal Biochem 388:317-321

41. Cai S, Dufner-Beattie JL, Prestwich GD (2004) Anal Biochem 326:33-41

42. Lühn S, Schrader T, Sun W, Alban S (2010) J Pharm Biomed Anal 52:1-8

43. Wang M, Zhang D, Zhang G, Zhu D (2008) Chem Commun 4469-4471

44. Sauceda JC, Duke RM, Nitz M (2007) ChemBioChem 8:391394

45. Wang L, Buchanan S, Meyerhoff ME (2008) Anal Chem 80:9845-9847

46. Wang L, Meyerhoff ME (2010) Electroanalysis 22:26-30

47. Holzgrabe U (2009) Pharm Ind 71:2102-2108

48. Spencer JA, Kauffman JF, Reepmeyer JC, Gryniewicz CM, Ye W, Toler DY, Buhse LF, Westenberger BJ (2009) J Pharm Sci 98:3540-3547

49. Sun C, Zang H, Liu X, Dong Q, Li L, Wang F, Sui L (2010) J Pharm Biomed Anal 51:1060-1063

50. Zhang ZQ, Xie J, Zhang FM, Linhardt RJ (2007) Anal Biochem 371:118-120

51. Zhang Z, Xiao Z, Linhardt RJ (2009) J Liq Chromatogr R T 32:1711-1732

52. Viskov C, Bouley E, Hubert P, Martinez C, Herman F, Jeske W, Hoppensteadt D, Walenga JM, Fareed J (2009) Clin Appl Thromb-Hemost 15:395-401

53. Guerrini M, Shriver Z, Naggi A, Casu B, Linhardt RJ, Torri G, Sasisekharan R (2010) Nat Biotech 28:207-211

54. Holzgrabe U, Diehl BWK, Wawer I (1998) J Pharm Biomed Anal 17:557-616

55. Holme KR, Perlin AS (1989) Carbohydr Res 186:301-312

56. Toida T, Huang Y, Washio Y, Maruyama T, Toyoda H, Imanari T, Linhardt RJ (1997) Anal Biochem 251:219-226

57. Atha DH, Coxon B, Reipa V, Gaigalas AK (1995) J Pharm Sci $84: 360-364$

58. Sugahara K, Tsuda H, Yoshida K, Yamada S, de Beer $T$, Vliegenthart JFG (1995) J Biol Chem 270:22914-22923

59. Chuang W-L, Christ MD, Rabenstein DL (2001) Anal Chem 73:2310-2316

60. Ruiz-Calero V, Saurina J, Galceran MT, Hernandez-Cassou S, Puignou L (2000) Analyst 125:933-938 
61. McEwen I, Rundlof T, Ek M, Hakkarainen B, Carlin G, Arvidsson T (2009) J Pharm Biomed Anal 49:816-819

62. McEwen I (2010) J Pharm Biomed Anal 51:733-735

63. Beyer T, Diehl B, Randel G, Humpfer E, Schafer H, Spraul M, Schollmayer C, Holzgrabe U (2008) J Pharm Biomed Anal 48:13-19

64. Tachibana S, Nishiura S, Ishida S, Kakehi K, Honda S (1990) Chem Pharm Bull 38:2503-2506

65. Yamaguchi H, Shinagawa M, Shimba N, Miyano H, Suzuki E (2008) Yakugaku Zasshi (J Pharm Soc Jpn) 128:1513-1515

66. Guerrini M, Shriver Z, Bisio A, Naggi A, Casu B, Sasisekharan R, Torri G (2009) Thromb Haemost 102:907-911

67. Bigler P, Brenneisen R (2009) J Pharm Biomed Anal 49:1060 1064

68. Beyer T, Matz M, Brinz D, Rädler O, Wolf B, Norwig J, Baumann K, Alban S, Holzgrabe U (2010) Eur J Pharm Sci 40:297-304

69. Keire DA, Trehy ML, Reepmeyer JC, Kolinski RE, Ye W, Dunn J, Westenberger BJ, Buhse LF (2010) J Pharm Biomed Anal 51:921-926

70. Keire DA, Mans DJ, Ye H, Kolinski RE, Buhse LF (2010) J Pharm Biomed Anal 52:656-664

71. Jayawickrama DA, Larive CK, McCord EF, Roe DC (1998) Magn Reson Chem 36:755-760

72. Kellenbach E, Burgering M, Kaspersen F (1999) Org Process Res Dev 3:141-144

73. Sitkowski J, Bednarek E, Bocian W, Kozerski L (2008) J Med Chem 51:7663-7665

74. Bednarek E, Sitkowski J, Bocian W, Mulloy B, Kozerski L (2010) J Pharm Biomed Anal 53:302-308

75. Jones DNM, Bendiak B (1999) J Biomol NMR 15:157-168

76. Bendiak B, Fang TT, Jones DNM (2002) Can J Chem 80:10321050

77. Chrambach A, Rodbard D (1971) Science 172:440-451

78. Hampson IN, Gallagher JT (1984) Biochem J 221:697-705

79. Rice KG, Rottink MK, Linhardt RJ (1987) Biochem J 244:515522

80. Edens RE, Al-Hakim A, Weiler JM, Rethwisch DG, Fareed J, Linhardt RJ (1992) J Pharm Sci 81:823-827

81. Al-Hakim A, Linhardt RJ (1990) Electrophoresis 11:23-28

82. Laremore TN, Ly M, Solakyildirim K, Zagorevski DV, Linhardt RJ (2010) Anal Biochem 401:236-241

83. Zhang ZQ, Li BYZ, Suwan J, Zhang FM, Wang ZY, Liu HY, Mulloy B, Linhardt RJ (2009) J Pharm Sci 98:4017-4026

84. Volpi N, Maccari F, Linhardt RJ (2008) Electrophoresis 29:3095-3106

85. Zamfir A, Peter-Katalinic J (2004) Electrophoresis 25:19491963

86. Grimshaw J (1997) Electrophoresis 18:2408-2414

87. Stefansson M, Novotny M (1994) Anal Chem 66:3466-3471
88. Ampofo SA, Wang HM, Linhardt RJ (1991) Anal Biochem 199:249-255

89. Desai UR, Wang HM, Ampofo SA, Linhardt RJ (1993) Anal Biochem 213:120-127

90. Pervin A, Alhakim A, Linhardt RJ (1994) Anal Biochem 221:182-188

91. McCormick RM (1988) Anal Chem 60:2322-2328

92. Eldridge SL, Higgins LA, Dickey BJ, Larive CK (2009) Anal Chem 81:7406-7415

93. Militsopoulou M, Lamari FN, Hjerpe A, Karamanos NK (2002) Electrophoresis 23:1104-1109

94. Ruiz-Calero V, Moyano E, Puignou L, Galceran MT (2001) J Chromatogr A 914:277-291

95. King JT, Desai UR (2008) Anal Biochem 380:229-234

96. Duchemin V, Potier IL, Troubat C, Ferrier D, Taverna M (2002) Biomed Chromatogr 16:127-133

97. Patel RP, Narkowicz C, Hutchinson JP, Hilder EF, Jacobson GA (2008) J Pharm Biomed Anal 46:30-35

98. Wielgos T, Havel K, Ivanova N, Weinberger R (2009) J Pharm Biomed Anal 49:319-326

99. Somsen GW, Tak YH, Torano JS, Jongen P, de Jong GJ (2009) J Chromatogr A 1216:4107-4112

100. Volpi N, Maccari F, Linhardt RJ (2009) Anal Biochem 388:140-145

101. Kakoi N, Kinoshita M, Kawasaki N, Yamaguchi T, Hayakawa T, Kakehi K (2009) Yakugaku Zasshi (J Pharm Soc Jpn) 129:12551264

102. Chuang W-L, McAllister H, Rabenstein DL (2001) J Chromatogr A 932:65-74

103. Chuang W-L, McAllister H, Rabenstein DL (2002) Carbohydr Res 337:935-945

104. Rice KG, Kim YS, Grant AC, Merchant ZM, Linhardt RJ (1985) Anal Biochem 150:325-331

105. Limtiaco JFK, Jones CJ, Larive CK (2009) Anal Chem $81: 10116-10123$

106. Hashii N, Kawasaki N, Itoh S, Qin Y, Fujita N, Hattori T, Miyata K, Bando A, Sekimoto Y, Hama T, Kashimura M, Tatsumi M, Mabuchi K, Namekawa H, Sakai T, Hirose M, Dobashi S, Shimahashi H, Koyama S, Herr SO, Kawai K, Yoden H, Yamaguchi $\mathrm{T}$ (2010) Biologicals (in press). doi:10.1016/ j.biologicals.2010.04.002

107. Karamanos NK, Vanky P, Tzanakakis GN, Tsegenidis T, Hjerpe A (1997) J Chromatogr A 765:169-179

108. Thanawiroon C, Linhardt RJ (2003) J Chromatogr A 1014:215-223

109. Thanawiroon C, Rice KG, Toida T, Linhardt RJ (2004) J Biol Chem 279:2608-2615

110. Kuberan B, Lech M, Zhang L, Wu ZL, Beeler DL, Rosenberg RD (2002) J Am Chem Soc 124:8707-8718

111. Jones CJ, Membreno N, Larive CK (2010) J Chromatogr A 1217:479-488

112. Volpi N, Linhardt RJ (2010) Nat Protoc 5:993-1004 